\title{
AN EMERGENCY BOTTLE FOR DRIED PLASMA
}

\author{
BY \\ WALTER KOCH \\ Department of Hygiene, Hebrew University, Jerusalem
}

(RECEIVED FOR PUblication, APRIL 24, 1948)

Dried plasma is usually kept in evacuated, rubber-stoppered bottles. Reconstitution calls for a series of additional gadgets as the water has to be transferred from its bottle to the plasma bottle, and two rubber tubings have to be inserted in order to give access to the air and to carry the dissolved plasma. Furthermore, if the vacuum in the plasma bottle has decayed, the water has to be pumped over with a blowing ball. All these manipulations are not always easily performed in the field.

An attempt has therefore been made to design an emergency bottle for quickly reconstituting dried plasma. The underlying principle is that of the fire-extinguisher in which the contents are mixed after an ampoule has been crushed.

\section{The Emergency Bottle}

The emergency bottle (see Figure) consists of a cylindrically shaped outer vessel (1) whose lower end

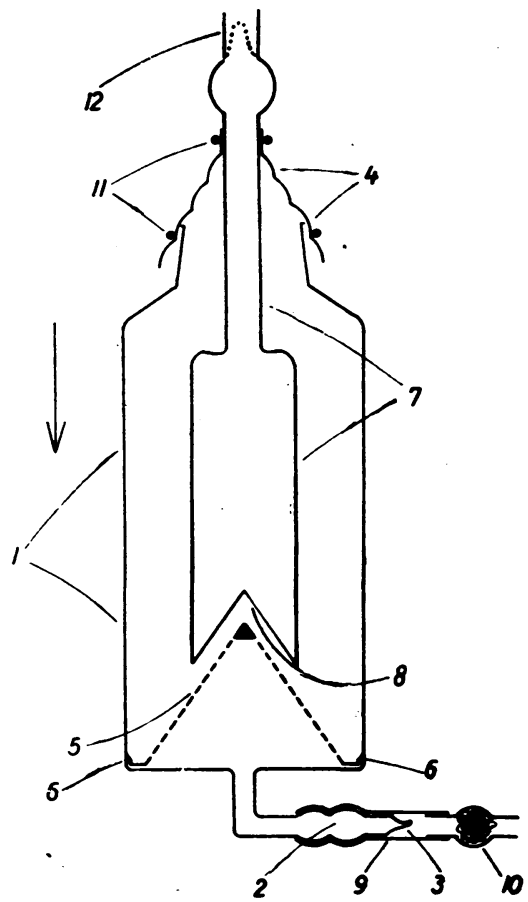

forms an olive (2), drawn out to a point and sealed (3). The wide upper mouth of this vessel forms a brim which engages a bellow-shaped rubberconnexion (4). On the bottom of the vessel rests a cone of stainless steel (5) with reinforced tip. This cone is a sieve with holes of about $1 \frac{1}{2} \mathrm{~mm}$. diameter resembling an inverted filter-cone. Its rim is flattened and is kept towards the bottom of the outer vessel (1) by four protrusions of the glass (6). The inner vessel (7) is a big ampoule with a stout neck which passes the rubber-connexion (4). The bottom (8) of the ampoule is drawn in and thinned. The neck of the ampoule is dilated near its top after the rubberconnexion (4) has been pushed over. This bellowshaped rubber-connexion is cheaply available as rubber push-on connector for gas or water tubing ; for larger bottles small rubber showers that may be attached directly to taps are a satisfactory alternative if the perforated plate is removed. A short piece of thick (pressure) rubber tubing (9), pushed over the olive, protects the drawn-out tip (3), and leads to a glass bulb (10). This bulb (10) is stuffed with $28-$ to 32-gauge bandage and acts as a filter. The free end of the bulb is connected to a needle protected against contamination (not shown in the drawing). A sintered glass pipeline filter would probably be better than gauze bandage, but this could not be tried*; when assembling the apparatus, distilled water is filled into the outer vessel (1) and all parts are sterilized in the autoclave. The connector (4) is then secured to both vessels by circular wires (11). The distance between the bottom of the ampoule (8) and the steel cone (5) is determined by the flexibility of the rubber piece (4) so that accidental movements of the ampoule should not engage the steel cone. The ampoule (7) is dried by connecting to a pump, and dried plasma is then filled into the ampoule. The bulb in the neck of the ampoule is plugged with sterile cotton wool, evacuated, and sealed at (12) (dotted line).

When needed, the inner vessel (7) is pushed into the outer (1), in the direction indicated by the arrow. As soon as the bottom of the ampoule (8) is crushed, water is drawn in and mixes with the dry plasma. Shaking aids dissolution of the plasma. Then the tip of the ampoule (12) is opened to give access to the air, and flow of the plasma is started by bending the rubber tubing (9) whereby the tip (3) is being broken. The vessels can be re-used.

* Messrs. Baird and Tatlock, London, recommend their K.301 H.3 or K.301 H.4 filter tube as a suitable sintered filter. 